Journal of Clinical Investigation

Vol. 41, No. 5, 1962

\title{
THE METABOLISM OF DESMOSTEROL IN HUMAN SUBJECTS DURING TRIPARANOL ADMINISTRATION *
}

\author{
By DeWITT S. GOODMAN, JOEL AVIGAN AND HILDEGARD WILSON \\ (From the Section on Metabolism, National Heart Institute, and the National Institute of \\ Arthritis and Metabolic Diseases, Bethesda, Md.)
}

(Submitted for publication October 25, 1961 ; accepted January 25, 1962)

Recent studies with triparanol (1- $[p-\beta$-diethylaminoethoxyphenyl]-1-( $p$-tolyl $)-2-(p$-chlorophenyl)ethanol) have demonstrated that this compound inhibits cholesterol biosynthesis by blocking the reduction of 24-dehydrocholesterol (desmosterol) to cholesterol (2-4). Administration of triparanol to laboratory animals and to man results in the accumulation of desmosterol in the plasma and tissues, usually with some concomitant lowering of the plasma total sterol concentration $(2,5)$. In studies with human subjects it was observed that after about 2 weeks the desmosterol concentration tended to plateau at an average level of 27 per cent of the total circulating sterols (5). The ratios of desmosterol to cholesterol in animal tissues (2) differed somewhat from the ratios in plasma. In addition, injection of the cholesterol precursor 2- $\mathrm{C}^{14}$-mevalonic acid during triparanol administration resulted in the rapid appearance of labeled desmosterol in blood, while no significant radioactivity appeared in cholesterol in the first few days (5).

The object of the present experiments was to study the metabolism of desmosterol in patients receiving triparanol. Since cholesterol serves as the biosynthetic precursor for several physiologically important compounds, including bile acids and steroid hormones, the question arose whether desmosterol could also function as a precursor for these compounds without first being transformed into cholesterol. The studies reported herein demonstrate the direct conversion of desmosterol to both bile acids and to steroid hormones, and also provide information about the over-all metabolism of this sterol in the triparanol-treated man.

\section{EXPERIMENTAL}

Clinical material. Both of the patients studied were hospitalized on a metabolic ward of the Clinical Center.

* Presented in part at the First International Pharmacology Meeting, Stockholm, Sweden, August, 1961 (1).
Patient G.B. was a 55 year old man with known arteriosclerotic heart disease and mild hypercholesterolemia; since 1957 he had maintained a satisfactory and stable cardiac status. At the time of the present study he had been taking $250 \mathrm{mg}$ triparanol daily for 4 weeks, and had a total serum sterol level in the high normal range. Patient F.A. was a 40 year old man with a 4 - to 5-year history of gout and essential hyperlipemia. At the time of this study he had been on an isocaloric low purine diet for several weeks, and both the gout and hyperlipemia were in remission. He received $250 \mathrm{mg}$ triparanol daily for 2 weeks prior to the start of this study.

Design of study. Each study was begun in the fasting patient by the rapid injection of $20 \mu \mathrm{c}$ of $2-\mathrm{C}^{\mathbf{1 4}}$-mevalonic acid, in isotonic saline, into an antecubital vein. Patient F.A. also received, in the same injection, $20 \mu \mathrm{c}$ of $7-\alpha \mathrm{H}^{3}-$ cholesterol, previously incorporated into his own serum lipoproteins by the method of Avigan (6). Blood samples were collected 3 hours later from the opposite antecubital vein, and at varying intervals thereafter. We obtained bile in the early mornings by duodenal intubation, employing intravenous cholecystokinin when necessary, to ensure an adequate sample, and also collected 24-hour urine samples, using small amounts of toluene as preservative.

Serum sterols. Sera were extracted with 25 vol of alcohol: acetone, $1: 1$ ( $\mathrm{vol} / \mathrm{vol})$, and the free sterols were precipitated from these extracts as their digitonide complexes. After collection of the digitonide precipitates, the supernatants were saponified with ethanolic $\mathrm{KOH}$, neutralized with acetic acid, and the hydrolyzed ester sterols were precipitated as digitonides. The sterol digitonides thus derived from the free and ester sterol fractions were then washed, cleaved with pyridine, and the sterols extracted, washed, and dried as described by Steinberg, Avigan and Feigelson (5). The sterol fractions so obtained, consisting of mixtures of desmosterol and cholesterol, will subsequently be referred to as unfractionated free or ester sterols. Small portions of the unfractionated sterols were used for the measurement of cholesterol and desmosterol in the sample, by the differential colorimetric method of Avigan and co-workers (2). Other portions of the sterols were directly assayed for radioactivity, and the specific radioactivities were determined. The remaining unfractionated sterols of each sample were separated into cholesterol and desmosterol by chromatography of their $p$-phenylazobenzoyl esters on columns of silicic acid: Celite, 2:1 (2). The purified cholesterol and desmosterol fractions were then individually 
assayed for radioactivity and were also colorimetrically analyzed for cholesterol and desmosterol. Cholesterol was usually obtained free of desmosterol, but the desmosterol samples were generally contaminated with small amounts of cholesterol. As discussed elsewhere, however (5), by knowing the analytical values for the purified sterols in the samples counted, it was possible to calculate with precision the individual specific radioactivities of cholesterol and desmosterol, despite the contamination of the desmosterol samples with small amounts of cholesterol. An internal check on the accuracy of these determinations was provided by the specific radioactivity measurements of the unfractionated sterols. The calculated and measured values for specific radioactivity of the unfractionated sterols agreed closely in all cases.

Bile. Bile samples were extracted with 25 vol of ethanol. Each ethanol extract was evaporated nearly to dryness and saponified with $\mathrm{NaOH}$ under pressure. The unsaponifiable fraction was then extracted with ethyl ether, followed by acidification of the sample and extraction of the acidic fraction with ethyl ether. Cholic acid was purified from the acidic fraction of the bile of $\mathrm{Pa}$ tient G.B. by reversed-phase partition chromatography, with methanol-water as moving phase and isooctanolchloroform as stationary phase, as described by Norman (7) and Sjövall (8). A mixture of chenodeoxy- and deoxycholic acids was purified from the acidic fractions of the bile samples of Patient F.A. by partition chromatography as described by Mosbach, Zomzely and Kendall (9), with acetic acid on Celite as stationary phase and isopropyl ether-petroleum ether mixtures as mobile phase. The amount of purified bile acid obtained was determined by weighing the material after crystallization and drying; verification of these values was secured by spectrophotometric analyses of aliquots of the samples by the method of Mosbach, Kalinsky, Halpern and Kendall (10). The specific radioactivity of the bile acids was obtained by radioassay of a measured aliquot of the purified sample.

In some samples sterols were precipitated from the unsaponifiable fraction of bile as their digitonide complexes, analyzed colorimetrically, and counted to determine specific radioactivity.

Urinary steroids. ${ }^{1}$ Ether extracts of the neutral ster-

1 Trivial names of the steroids used in this paper follow. Etiocholanetrione: etiocholane-3,11,17-trione. THF : $3 \alpha, 11 \beta, 17 \alpha, 21$-tetrahydroxypregnane-20-one. THE: $3 \alpha,-$ 17 $\alpha, 21$-trihydroxypregnane-11,20-dione. 11-Ketoetiocholanolone : $3 \alpha$-hydroxyetiocholane-11,17-dione. $11-\mathrm{Hy}$ droxyetiocholanolone : $3 \alpha, 11 \beta$-dihydroxyetiocholane-17-one. 11 -Hydroxyandrosterone : $3 \alpha, 11 \beta$-dihydroxyandrostane-17one. Etiocholanolone: $3 \alpha$-hydroxyetiocholane-17-one. Androsterone: $3 \alpha$-hydroxyandrostane-17-one. Adrenosterone : $\Delta^{4}$-androstene-3,11,17 - trione. Androstanediol : androstane- $3 \alpha, 17 \alpha$-diol, dihydroandrosterone. Cortisol : $11 \beta, 17 \alpha$,21 -trihydroxy-4-pregnene-3,20-dione. Corticosterone:11 $\beta,-$ 21 -dihydroxy -4 - pregnene-3,20-dione. Etiocholanedione : etiocholane-3,17-dione. Androstanedione : androstane-3,17dione. oids were obtained from the 24-hour urine samples by incubation of the urine with $\beta$-glucuronidase, followed by acidification, continuous ether extraction for 72 hours, and appropriate washings of the ether extract to remove acids and phenolic compounds $(11,12)$. In the first study (Patient G.B.), the neutral extract was then directly oxidized with chromic acid $\left(\mathrm{CrO}_{3}\right)$ solution by a slightly modified procedure of Wotiz, Lemon and Marcus (13). The $\mathrm{CrO}_{3}$ oxidation converts most cortisol metabolites to etiocholanetrione; the other metabolites giving significant amounts of this product are the $\mathrm{C}_{10} \mathrm{O}_{3}$ steroids (e.g., 11-hydroxyetiocholanolone). This procedure, consequently, provided enough of a single compound for accurate determination of specific radioactivity. The excess $\mathrm{CrO}_{3}$ was reduced with 0.2 per cent $\mathrm{NaHSO}_{3}$ and the steroids extracted with methylene chloride. This extract was washed with $0.1 \mathrm{~N} \mathrm{NaOH}$ and with water, and then prepared for paper chromatography.

In the second study (Patient F.A.) the entire extract of each urine was first subjected to partition column chromatography as described elsewhere (11), with a column of $15 \mathrm{~g}$ aluminum silicate and 50 per cent ethanol as stationary phase. The elution sequence was simplied so that only two fractions were collected: 1 ) $200 \mathrm{ml} 15$ per cent chloroform in hexane; and 2) 260 $\mathrm{ml} 30$ per cent chloroform in hexane, followed by $120 \mathrm{ml}$ 50 per cent chloroform in hexane. The first fraction contained all $\mathrm{C}_{19} \mathrm{O}_{2}$ and $\mathrm{C}_{19} \mathrm{O}_{3}$ (and any $\mathrm{C}_{21} \mathrm{O}_{4}$ ) steroids; the second fraction contained all $\mathrm{C}_{21} \mathrm{O}_{5}$ and $\mathrm{C}_{21} \mathrm{O}_{6}$ metabolites present (i.e., all the cortisol metabolites and little or nothing else). Paper chromatograms run on aliquots of both fractions showed that in all cases the column had effected the desired separation. These spot tests also proved that the patient was excreting the normal major steroid metabolites in his urine. Thus the cortisol metabolite fraction included both $\mathrm{THF}$ and $\mathrm{THE}$; the $\mathrm{C}_{19} \mathrm{O}_{3}$ steroids present included 11-ketoetiocholanolone, 11hydroxyetiocholanolone (in lesser amounts), and 11-hydroxyandrosterone; the $\mathrm{C}_{19} \mathrm{O}_{2}$ steroids were represented by a band corresponding to etiocholanolone and androsterone (which would not separate in the system used).

Each column fraction from the urine samples of $\mathrm{Pa}$ tient F.A. was then subjected to chromic acid oxidation, as described above, followed by paper chromatography of the oxidized steroids. The oxidized steroid fractions, except the $\mathrm{C}_{19} \mathrm{O}_{2}+\mathrm{C}_{19} \mathrm{O}_{3}$ fractions of F.A., were chromatographed on paper with a Bush "A2" system (ligroin: methanol: water, 100:70:30) for 6 hours (14). Test strips were analyzed by the Zimmermann reaction for 17 ketosteroids. The oxidized extracts showed a strong band corresponding to etiocholanetrione, and a weaker band corresponding to adrenosterone. The etiocholanetrione bands were cut out and eluted with ethanol by descending capillary flow. An aliquot was assayed by the micro-Zimmermann reaction (15), and the remainder was used for radioassay.

The oxidized $\mathrm{C}_{19} \mathrm{O}_{2}+\mathrm{C}_{19} \mathrm{O}_{3}$ fractions of F.A. were chromatographed on paper with the Bush "Al" system 
TABLE I

Specific radioactivity of serum sterols and of sterol metabolites after $C^{14}$-mevalonate, during treatment with triparanol, in Patient G.B.

\begin{tabular}{|c|c|c|}
\hline Compound analyzed & $\begin{array}{c}\text { Sample } \\
\text { obtained at: }\end{array}$ & $\begin{array}{c}\text { Specific } \\
\text { radio } \\
\text { activity }\end{array}$ \\
\hline & & $\mathrm{cpm} / \mu \mathrm{mole}$ \\
\hline Serum free desmosterol & 3 hrs & 452 \\
\hline Serum free cholesterol & $3 \mathrm{hrs}$ & 0 \\
\hline Serum unfract. free sterols & $3 \mathrm{hrs}$ & 154 \\
\hline Serum free desmosterol & 3 days & 99.5 \\
\hline Serum free cholesterol & 3 days & 5.1 \\
\hline Serum unfract. free sterols & 3 days & 33.6 \\
\hline $\begin{array}{l}\text { Red cells, unfract. free } \\
\text { sterols }\end{array}$ & 3 days & 36.4 \\
\hline Cholic acid from bile & 3 days & 30.1 \\
\hline Cortisol derivs. from urine & 3-4 days & 37.7 \\
\hline
\end{tabular}

(ligroin : methanol: water, $100: 90: 10$ ). These chromatograms showed bands corresponding to etiocholanetrione (from $\mathrm{C}_{19} \mathrm{O}_{3}$ metabolites) and also strong, less polar bands containing mixtures of androstanedione (oxidation product of androsterone and androstanediol) and etiocholanedione (oxidation product of etiocholanolone and etiocholanediol); both "diones" (to be referred to as "androgen derivatives") are derived from urinary $\mathrm{C}_{19} \mathrm{O}_{2}$ steroids and do not separate in the chromatographic system used. These bands were eluted, assayed against an androstanedione reference standard (the chromogenic value of etiocholanedione is very close to that of androstanedione), and radioassayed.

Radioassay was performed with a Packard liquid scintillation spectrometer. Sterols and oxidized steroids were dissolved in $15 \mathrm{ml} 0.5$ per cent diphenyloxazole (DPO) in toluene for counting; bile acids were first dissolved in $1 \mathrm{ml} p$-dioxane, followed by the addition of $15 \mathrm{ml} \mathrm{DPO}$ in toluene. All samples from F.A., together with absolute $\mathrm{C}^{14}$ and $\mathrm{H}^{3}$ standards, were simultaneously counted for $\mathrm{C}^{14}$ and $\mathrm{H}^{3}$ by using appropriate settings for the discriminators of the two channels. The quenching of each isotope was individually corrected by counting the samples again after the addition of a $\mathrm{H}^{3}$ internal standard, and then after addition of a $\mathrm{C}^{\mathbf{1 4}}$ internal standard. Counting efficiencies for the double-isotope procedure were 35 per cent for $\mathrm{C}^{14}$ and 18 per cent for $\mathrm{H}^{3}$; when $\mathrm{C}^{14}$ was counted alone, the efficiency was 52 per cent.

Materials. DL-2-C $\mathrm{C}^{\mathbf{1 4}}$-mevalonic acid (specific activity, $2.7 \mathrm{mc}$ per mmole) was obtained from the Volk Radiochemical Corp. 7- $\alpha-\mathrm{H}^{3}$-cholesterol (specific activity, 5.4 mc per mmole) was a product of the New England $\mathrm{Nu}-$ clear Corp. Pure desmosterol, for colorimetric standard, was isolated from livers of rats fed triparanol, as previously described (3). Cholic and deoxycholic acids, for use as analytic and chromatographic standards, were obtained from Nutritional Biochemicals Corp. The reference steroids were obtained from USP reference standards. Cholecystokinin (Cecekin) was obtained from the
Vitrum Pharmaceutical Co. of Stockholm. The isotopecontaining solutions for intravenous injection were prepared by the Pharmacy Department of the Clinical Center of the National Institutes of Health.

Correction of results. Cholesterol molecules synthesized from 2-C ${ }^{16}$-mevalonate contain five labeled carbon atoms : carbon atoms 1,7 , and 15 in the sterol nucleus and carbon atoms 22 and 27 in the side chain $(16,17)$. Desmosterol synthesized from $2-\mathrm{C}^{14}$-mevalonate should have the same pattern of labeling. On conversion of this kind of labeled cholesterol, or desmosterol, to bile acids, the one labeled carbon atom in the terminal isopropyl group (carbon atom 27) is lost. Similarly, two of the five labeled atoms (nos. 22 and 27) are lost during the removal of the terminal six carbons of the side chain, en route to steroid hormones (18). The results that follow have been corrected for the above losses by multiplying the measured bile acid $\mathrm{C}^{16}$ specific radioactivities by $5 / 4$, and the corresponding steroid $\mathrm{C}^{14}$ specific activities by $5 / 3$.

\section{RESULTS}

For Patient G.B. the specific activities of the serum sterols were determined after 3 hours and after 3 days. Table I demonstrates that at 3 hours there was considerable radioactivity in serum free desmosterol (452 cpm per $\mu$ mole) but no measurable radioactivity in cholesterol. After 3 days the specific activity of desmosterol had decreased to $99.5 \mathrm{cpm}$ per $\mu$ mole and a little radioactivity (5.1 cpm per $\mu$ mole) was detectable in cholesterol. The specific activity of the unfractionated sterols at both 3 hours and 3 days reflects the fact that in this patient about one-third of the serum sterols was desmosterol and two-thirds cholesterol.

The ratio of desmosterol to cholesterol in the unfractionated red cell sterols obtained after 3 days was very similar to that in plasma. This fact, plus the closeness of the specific radioactivities of the unfractionated free sterols of serum and red cells (see Table I), suggests that desmosterol and cholesterol of serum and red cells were in isotopic equilibrium.

After 3 days, bile and urine were collected, from which cholic acid and the cortisol derivatives (plus $\mathrm{C}_{19} \mathrm{O}_{3}$ derivatives, as etiocholanetrione : vide supra) were respectively isolated. Both cholic acid and the cortisol derivatives had specific radioactivity much greater than that of serum cholesterol (see Table I), demonstrating that a significant part of these materials must have been synthesized directly from desmosterol.

The second study, with Patient F.A. as subject, 
was more elaborate in that samples were collected at 1- or 2-day intervals for a week. In addition, as already mentioned, $\mathrm{H}^{3}$-labeled cholesterol was injected simultaneously with the $\mathrm{C}^{14}$-mevalonate. For the sake of clarity, however, the $\mathrm{C}^{14}$ data from this study will initially be presented alone.

Figure 1 shows the $\mathrm{C}^{14}$ specific radioactivity of the serum free and esterified desmosterol and unfractionated sterols. The $\mathrm{C}^{14}$ specific radioactivity of all cholesterol samples was below 10 , and hence is not shown in this semilogarithmic plot. The $\mathrm{C}^{14}$ specific radioactivity of cholesterol ranged from 6.2 at 3 hours to $7.7 \mathrm{cpm}$ per $\mu$ mole at 7 days for free cholesterol, and from 2.3 to $7.3 \mathrm{cpm}$ per $\mu$ mole for esterified cholesterol. These low values constituted, however, a significant portion of the total radioactivity by 7 days. The ratio of desmosterol to cholesterol was remarkably constant during the study period; desmosterol comprised 32 to 34 per cent of the total serum sterols in all six samples.

Figure 2 shows the corrected $\mathrm{C}^{14}$ specific activity of the bile acids from Patient F.A., compared with the specific activity curve of serum free desmos-

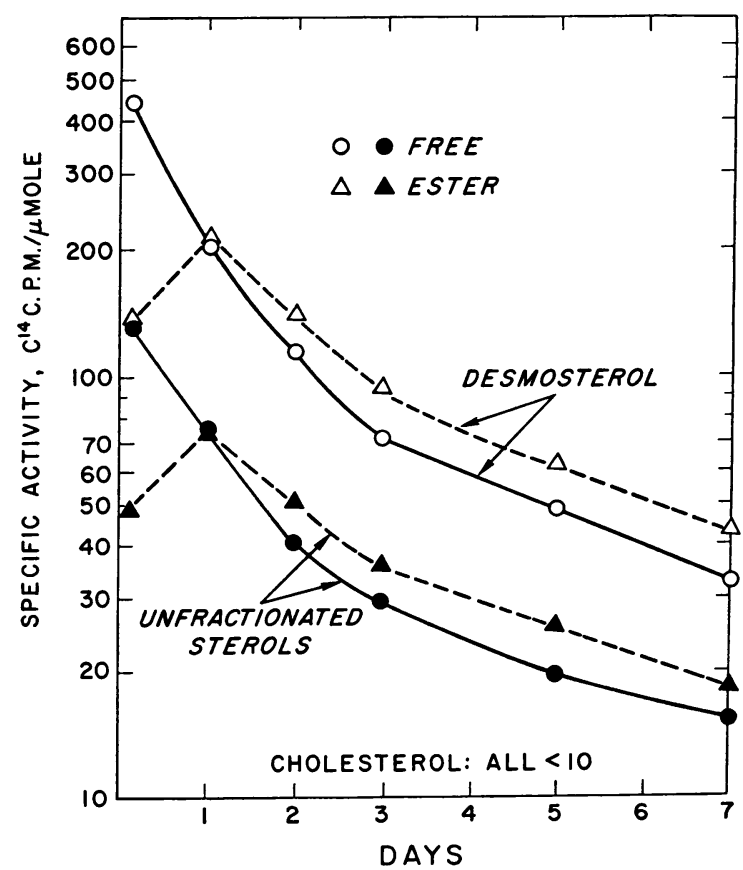

Fig. 1. C C $^{14}$ SPECIFIC RADIOACTIVITY OF FREE AND ESTERIFIED STEROLS, DURING TRIPARANOL ADMINISTRATION, IN the SERUM of Patient F.A. After injection of 2- $\mathrm{C}^{16}$ MEVALONATE.

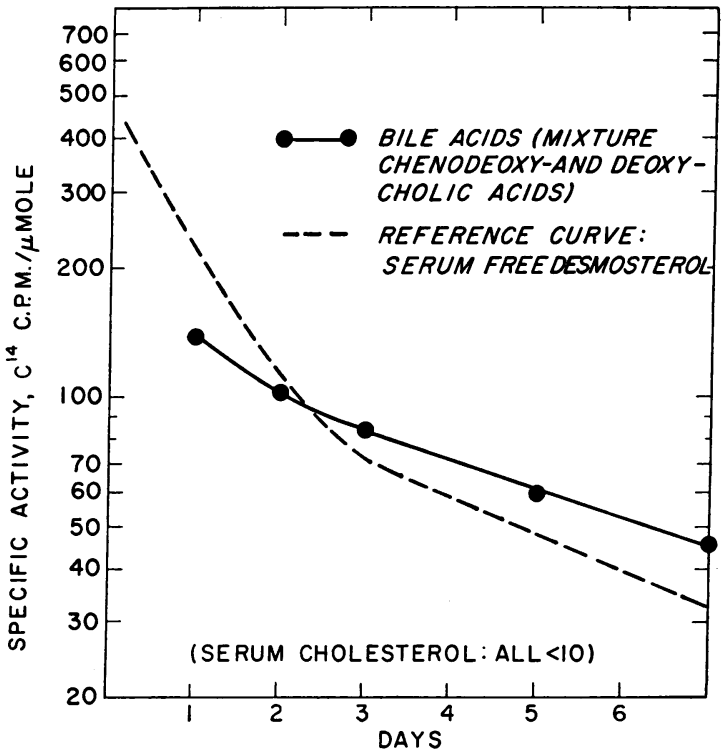

Fig. 2. $\mathrm{C}^{14}$ SPECIFIC RADIOACTIVITY OF THE BILE ACIDS of Patient F.A. during triparanol administration, AFTER INJECTION OF 2-C ${ }^{14}$-MEVALONATE.

terol. Because of a laboratory accident the cholic acid samples could not be obtained, and mixtures of chenodeoxy- and deoxycholic acids were purified and analyzed instead. It is evident that, throughout the period of study, the bile acid $\mathrm{C}^{14}$ specific radioactivity was much greater than that of serum cholesterol. This indicates that at least part of these acids must have been made directly from desmosterol.

Figure 3 shows similar data for the cortisol derivatives, analyzed as etiocholanetrione, and for the androgen derivatives, analyzed as "androstanedione," isolated from the urine samples of $\mathrm{Pa}$ tient F.A. The $\mathrm{C}^{14}$ specific radioactivity of both classes of steroids was much higher than that of cholesterol throughout the study, demonstrating that part of these steroids must have been made directly from desmosterol.

Let us now consider the double-isotope data obtained from Patient F.A. Figure 4 again shows the $\mathrm{C}^{14}$ specific radiactivity curves for serum free and esterified desmosterol, and also shows the $\mathrm{H}^{3}$ specific radioactivity curves for free and esterified cholesterol isolated from the same serum samples. The disappearance rates of cholesterol and desmosterol are fairly similar, desmosterol disappearance being a little more rapid than that of cholesterol. 


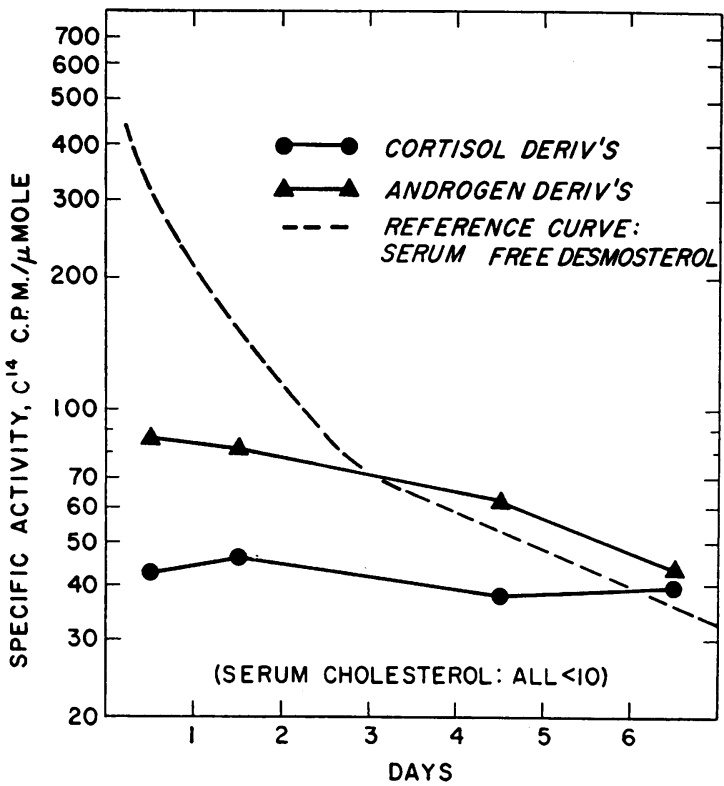

FIG. 3. $C^{14}$ SPECIFIC RADIOACTIVITY OF THE URINARY STEROID DERIVATIVES OF PATIENT F.A. DURING TRAPARANOL ADMINISTRATION, AFTER INJECTION OF 2 - $\mathrm{C}^{\mathbf{1 4}}$-MEVALONATE.

From these data information can be derived about the total metabolism of desmosterol in this patient. For this purpose it is necessary to assume that the mass ratio of cholesterol to desmos-

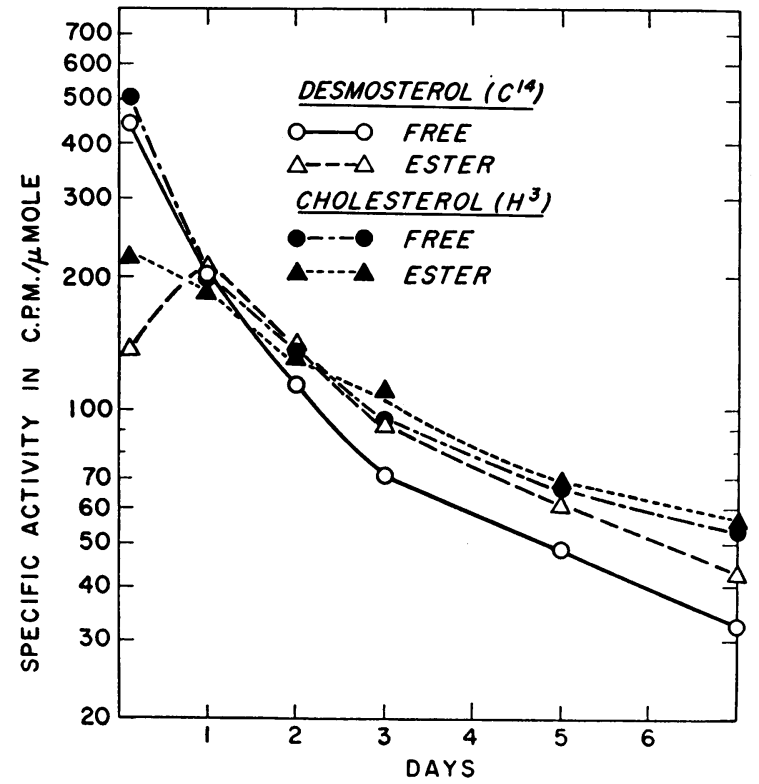

Fig. 4. SPECIFIC RADIOACTIVITY OF FREE AND ESTERIFIEd DESMOSTEROL $\left(\mathrm{C}^{14}\right)$ AND CHOLESTEROL $\left(\mathrm{H}^{8}\right)$ IN THE SERUM OF PATIENT F.A. DURING TRIPARANOL ADMINISTRATION, AFTER INJECTION OF 2-C ${ }^{14}$-MEVALONATE AND 7- ${ }^{3}$ CHOLESTEROL. In cpm of either $\mathrm{C}^{14}$ or $\mathrm{H}^{3}$ per $\mu$ mole sterol. terol in the entire metabolically active pool (i.e., the plasma-red cell-liver pool) was similar to that in plasma. This assumption is reasonable, since this ratio was very similar in red cells and plasma, and since even a moderate difference in the liver should have only a small effect on the sterol ratio of the entire pool. By then using the three sets of measurements-1) the rate of disappearance of $\mathrm{C}^{\mathbf{1 4}}$ in desmosterol, 2) the rate of disappearance of $\mathrm{H}^{3}$ in cholesterol, and 3) the rate of appearance of $\mathrm{C}^{14}$ in cholesterol-a calculation was made of the fraction of the disappearing $\mathrm{C}^{14}$ desmosterol that reappeared as $\mathrm{C}^{14}$-cholesterol. ${ }^{2}$ The calculation showed that in this patient $21 \pm 4$ per cent ( $\mathrm{SE}$ of mean) of the desmosterol which disappeared from the metabolically active pool re-

TABLE II

Specific radioactivity ratios of $H^{3}$ to $C^{14}(\mathrm{cpm} / \mu \mathrm{mole})$, after $C^{14}-m e v a l o n a t e$ and $H^{3}$-cholesterol during triparanol therapy in Patient F.A.

\begin{tabular}{|c|c|c|c|c|}
\hline \multirow[b]{2}{*}{$\begin{array}{l}\text { Sample } \\
\text { collected at: }\end{array}$} & \multicolumn{2}{|c|}{$\begin{array}{l}\text { Serum unfrac- } \\
\text { tionated sterols }\end{array}$} & \multicolumn{2}{|c|}{ Urinary steroids } \\
\hline & Free & Ester & $\begin{array}{l}\text { Cortisol } \\
\text { derivs. }\end{array}$ & $\begin{array}{c}\text { Androgen } \\
\text { derivs. }\end{array}$ \\
\hline $\begin{array}{l}3 \text { hrs } \\
1 \text { day } \\
2 \text { days } \\
3 \text { days } \\
5 \text { days } \\
7 \text { days }\end{array}$ & $\begin{array}{l}2.64 \\
1.74 \\
2.27 \\
2.12 \\
2.41 \\
2.40\end{array}$ & $\begin{array}{l}2.98 \\
1.75 \\
1.74 \\
2.12 \\
1.71 \\
2.07\end{array}$ & $\begin{array}{l}0.79 \\
0.67\end{array}$ & $\begin{array}{l}1.09 \\
0.78\end{array}$ \\
\hline
\end{tabular}

appeared therein as cholesterol. More than threefourths of desmosterol disappearance therefore occurred via other metabolic pathways. ${ }^{3}$

The use of $\mathrm{H}^{3}$-cholesterol together with $\mathrm{C}^{14}$ mevalonate also provided additional information about the relationship of the serum sterols to the

2 The difference between the disappearance rates of $\mathrm{C}^{14}$ and $\mathrm{H}^{3}$ in serum cholesterol represented the rate of synthesis of $\mathrm{C}^{14}$-cholesterol from $\mathrm{C}^{14}$-desmosterol. The disappearance rate of $\mathrm{C}^{16}$-desmosterol (in $\mathrm{cpm}$ per $\mathrm{mg}$ ), multiplied by the desmosterol: cholesterol mass ratio, gave the maximum possible increment in $\mathrm{C}^{14}$-cholesterol specific radioactivity, should cholesterol be the only end product of desmosterol metabolism. Comparison of the observed and maximum possible $\mathrm{C}^{14}$-cholesterol increments then yielded the fraction of disappearing desmosterol that reappeared as cholesterol in the metabolically active pool.

3 This is the maximum possible value for desmosterol disappearance via noncholesterol pathways, since some of the disappearing desmosterol might have been converted to cholesterol in tissue pools that are not in equilibrium with the serum cholesterol. Such conversion probably occurs only to a minor extent. 
urinary steroid metabolites in Patient F.A. Table II presents the ratios of $\mathrm{H}^{3}$ to $\mathrm{C}^{14}$, in counts per minute per micromole for each isotope, observed in the unfractionated serum sterols and in the urinary steroid derivatives. Both the cortisol and the androgen derivatives contained significant amounts of both $\mathrm{H}^{3}$ and $\mathrm{C}^{14}$ throughout the study. This indicates that both the serum cholesterol and desmosterol pools served as precursors for the two classes of steroids. The ratio of $\mathrm{H}^{3}$ to $\mathrm{C}^{14}$ was decidedly lower in the steroid derivatives than in the unfractionated serum sterols. As expected, only minute amounts of $\mathrm{H}^{3}$ were found in the bile acids from F.A. This agrees with the finding of Bergstrom and Lindstedt and their associates that 7 - $\alpha$-hydroxylation is an integral part of bile acid biosynthesis and that the formation of deoxycholic acid is due to subsequent bacterial action on cholic acid in the intestinal lumen $(19,20)$. The minute amounts of $\mathrm{H}^{3}$ (less than 15 per cent of the $\mathrm{C}^{14} \mathrm{cpm}$ per $\mu$ mole) observed in the bile acid samples might reflect some slight isotopic nonhomogeneity in the labeling of the $7-\alpha-\mathrm{H}^{3}$-cholesterol used.

\section{DISCUSSION}

The present study has demonstrated the direct conversion of desmosterol into bile acids and into steroid hormones during triparanol therapy. This conclusion can be drawn with a high degree of confidence from the finding that the $\mathrm{C}^{14}$ specific radioactivity of these two classes of metabolites, after $\mathrm{C}^{14}$-mevalonate injection, was considerably higher than that of the serum cholesterol.

Two possible criticisms may be raised here. First, was the radioactivity observed in the bile acids and urinary steroids solely derived from sterol precursors? Under normal conditions the natural D-isomer of mevalonic acid is rapidly and efficiently converted into cholesterol (21), and the latter serves as the normal precursor of the metabolites considered here. The products of the other quantitatively important pathway of mevalonate metabolism, prenoic acids, do not give rise to the steroidal ring structure (22). There is no basis for an assumption that treatment with triparanol should introduce new metabolic pathways for mevalonic acid, particularly since in these patients labeled mevalonate was rapidly converted into a sterol (desmosterol). Second, to what ex- tent does the specific radioactivity of the serum sterols reflect that of the precursor sterols in the organs synthesizing the metabolites under study? For the case of bile acid synthesis the serum free cholesterol has been shown to closely reflect the liver precursor sterol pool. Thus it is known that the liver free cholesterol pool is in rapid isotopic equilibrium with serum free cholesterol, and that the bile acids derived from the former are in rapid isotopic equilibrium with both (23). Furthermore, in the studies with Patient F.A. it was found that the specific radioactivities of both desmosterol and cholesterol isolated from bile were fairly close to the corresponding specific radioactivities of the serum sterols. In these samples desmosterol represented an average of 41 per cent of the total biliary sterols. It is thus certain that most of the radioactivity observed in the bile acids was directly derived from desmosterol. It is also possible that during the early hours of the studies labeled bile acids were formed from sterol precursors of desmosterol; no evidence is available on this subject. It is exceedingly unlikely, however, that any significant part of the radioactivity of the bile acids was derived from cholesterol, since this would require a precursor cholesterol pool of much higher specific radioactivity than the entire liver cholesterol pool, contrary to the studies quoted above. This would, moreover, require the existence of a special fraction of liver desmosterol reductase which was much less inhibited by triparanol than was the main body of this enzyme. Studies with animals and with liver homogenates do not support this possibility $(2,3)$.

Comparable detailed information about the adrenal (and testicular) sterol pools is not available for man. Animal studies have indicated that guinea pig adrenal gland cholesterol is never in isotopic equilibrium with plasma cholesterol (24), probably because of considerable endogenous adrenal sterol biosynthesis, coupled with slow equilibration. Urinary cortisol was, however, in isotopic equilibrium with adrenal cholesterol (24). In contrast, adrenal gland and plasma cholesterol did reach isotopic equilibrium in the rat (25). In the present studies, therefore, the plasma sterol specific radioactivities cannot be assumed to reflect closely those of the precursor adrenal sterol pools. The data in Table II do, in fact, suggest that the plasma and adrenal precursor sterol pools might 
have been different during the period of study with Patient F.A. This derives from the persistently large difference in the $\mathrm{H}^{3}$ to $\mathrm{C}^{14}$ ratio of the urinary steroids and that of the plasma unfractionated sterols. One explanation for this difference is the possibility that there was significant endogenous adrenal sterol biosynthesis from $\mathrm{C}^{14}$-mevalonate during the early hours of the study. If there were also a preference for endogenously synthesized sterol for the synthesis of steroid hormones, or very poor mixing of the endogenous and plasma sterol pools, or both, the observed lower $\mathrm{H}^{3}$ to $\mathrm{C}^{14}$ ratio in the urinary steroids would result. There are, of course, other possible explanations. Thus, if desmosterol were a better steroid precursor than is cholesterol, the lower ratio would result. In addition, a variety of other factors might be involved, such as different ratios of desmosterol to cholesterol in the different pools, variable rates of equilibration between the sterol pools, or a possible loss of $\mathrm{H}^{3}$ occurring during the conversion of $7-\mathrm{H}^{3}$-cholesterol to steroids because of labilization of the hydrogens at carbon 7 during the double bond shift from 5,6 to 4,5.

Despite the absence of detailed information about these factors, the data presented here provide strong evidence that desmosterol (perhaps together with its precursor sterols) can effectively serve as a direct precursor for steroid hormone synthesis. This derives from the fact that the urinary steroid $\mathrm{C}^{14}$ specific radioactivity was very much higher than that of plasma cholesterol throughout the study. In order for $\mathrm{C}^{14}$ to appear in the steroids via cholesterol it would be necessary for the adrenal precursor cholesterol pool to have had a much higher $\mathrm{C}^{14}$ specific radioactivity than the corresponding plasma pool had, particularly early in the study. This in turn would have required a lack of inhibition of adrenal desmosterol reductase by triparanol, in order to permit the early formation of $\mathrm{C}^{14}$-cholesterol from mevalonate. Animal studies (unpublished) have shown that desmosterol accumulation in adrenal glands is comparable with its accumulation in other tissues, indicating an inhibition of adrenal desmosterol reductase comparable with that found elsewhere. It is hence highly unlikely that the $\mathrm{C}^{14}$-labeled steroids were synthesized via cholesterol. Since desmosterol is the major labeled adrenal sterol after $\mathrm{C}^{14}$-mevalonate, it is probable that most of the $\mathrm{C}^{14}$ steroids were synthesized directly from desmosterol.

An approximate comparison of the abilities of desmosterol and cholesterol to serve as precursors for bile acids can be obtained from the specific radioactivity data. In the case of Patient G.B. the specific radioactivity of cholic acid was close to that of the serum (and red cell) unfractionated free sterols. This suggests that desmosterol and cholesterol were fairly similar in their ability to serve as precursors. In the case of Patient F.A., the $\mathrm{C}^{14}$ specific radioactivity of the bile acids was, in fact, greater than that of the serum unfractionated sterols throughout most of the study. It is thus clear that desmosterol is at least comparable with cholesterol in its ability to serve as a precursor of bile acids.

This conclusion is also consonant with the data on the over-all metabolism of desmosterol in Patient F.A., indicating that approximately threefourths of desmosterol disappeared by routes other than conversion to cholesterol. It is almost certain that these routes were the same ones normally involved in cholesterol metabolism, with conversion of sterol to bile acids and excretion of sterol in the feces being the quantitatively important processes.

Animal studies support this conclusion. Blohm, Kariga and Mackenzie (26) found that, after the injection of $\mathrm{C}^{14}$-mevalonate into triparanol-treated rats, a considerable part of the radioactivity administered appeared in the feces as bile acids. Furthermore, in vitro studies from this laboratory (to be published in detail elsewhere) have directly demonstrated that desmosterol and cholesterol are comparable substrates for oxidation by liver mitochondria from triparanol-treated mice.

Because of the uncertainty about the relations of the various pools involved in steroid biosynthesis, only a less satisfactory estimate can be made of the comparative abilities of the two sterols to serve as precursors of steroid hormones. The data do suggest, however, that the two sterols are probably comparable, since in both patients the steroid specific activities were similar to those of the bile acids and the unfractionated plasma sterols. At any rate, it is reasonably clear that desmosterol can serve as an effective precursor for steroid biosynthesis.

Since desmosterol is an effective precursor for 
these sterol metabolites, it is apparent that the enzymes involved in the splitting of the cholesterol side chain in the biosynthesis of bile acids and steroids do not require a great deal of structural specificity in the sterol side chain. In addition, these results raise the interesting possibility that even under normal conditions some bile acid and steroid biosynthesis takes place from sterol precursors other than cholesterol. In other words it is possible, during the bioysnthetic sequence from lanosterol to cholesterol, that some of the intermediate sterols could be used directly for the synthesis of bile acids or steroids. Whether this normally occurs to any extent is, of course, not known.

Several recent reports indicate that adrenal function seems to be reduced during triparanol administration. Melby, St. Cyr and Dale found that the production of cortisol and aldosterone was significantly reduced in normal subjects at a dosage of $1,000 \mathrm{mg}$ per day (27). Hollander, Chobanian and Wilkins noted a slight but statistically significant decrease in urinary 17 -hydroxycorticosteroid excretion during treatment of patients with $250 \mathrm{mg}$ triparanol daily; 17-ketosteroid excretion was, however, normal (28). Reduced adrenal vein corticosterone has also been observed during the administration of relatively much larger doses of triparanol to rats (29). In view of the present finding that desmosterol is a suitable precursor for steroid hormones of a qualitatively normal composition, it is quite possible that this decline in adrenal activity during triparanol therapy is not due to the blocking of the conversion of desmosterol to cholesterol per se, but to some other factor. This factor might well be relatively nonspecific, possibly related to a variety of toxic reactions noted in this laboratory (unpublished) during administration of relatively large doses of triparanol to animals. These effects include reduced weight gain and listlessness and induction of abortion in rats.

Somewhat opposing therapeutic implications can be drawn from the results of these studies. On the one hand, the fact that desmosterol can serve as a satisfactory precursor for bile acids and steroid hormones suggests that the partial replacement of cholesterol by desmosterol during triparanol administration is not likely in itself to disrupt seriously the over-all physiology of the body. On the other hand, these results add new information on the great similarity that exists between desmosterol and cholesterol. Avigan and Steinberg and their associates have already commented upon the similarities of these two sterols in their physical and chemical properties, and have noted the widespread distribution of desmosterol in many different tissues, and the comparable rates of esterification of the sterols in vivo $(2,5)$. It is now apparent that the two sterols also enter other biosynthetic reaction sequences in a similar fashion. It is hence likely that desmosterol will resemble cholesterol in its relationship to the development of atheromatous lesions or clinical atherosclerosis. Recent observations in this laboratory (Avigan, unpublished) have in fact indicated that desmosterol can be recovered from both normal and atheromatous aortae of animals being treated with triparanol. It is therefore probable that, as previously suggested (5), the best shortterm indicator of the potential value of triparanol therapy resides in its effect on the total sterol level, rather than on the cholesterol level per se. An average depression of total circulating sterols of 15 per cent has been reported (5). In addition, the long-term biological effects of this therapy still require further consideration.

\section{SUM MARY}

The conversion of 24-dehydrocholesterol (desmosterol) to bile acids and to steroid hormones during triparanol administration has been studied in two male subjects. In each study, DL-2-C ${ }^{14}-$ mevalonic acid was injected intravenously and the $\mathrm{C}^{14}$ specific radioactivity of serum desmosterol and cholesterol was determined after 3 hours and at 1- to 3-day intervals thereafter. Radioactivity rapidly appeared in desmosterol with peak specific activity obtained within a few hours; cholesterol $\mathrm{C}^{14}$ specific activity was very much lower during the first few days of each study. Bile samples were collected by duodenal intubation and the bile acids extracted and purified by column chromatography. The urinary metabolites of cortisol were extracted from 24-hour urine samples and purified by chromatography in one or two systems. In one study, derivatives of the urinary $\mathrm{C}_{19} \mathrm{O}_{2}$ steroids were separately isolated and purified. In both patients the $\mathrm{C}^{14}$ specific radioactivity of the 
bile acids and steroids was much higher than that of cholesterol throughout the study, demonstrating that a significant part of these compounds must have been made directly from desmosterol.

In one study $7-\alpha-\mathrm{H}^{3}$-cholesterol, previously incorporated into the patient's serum lipoproteins, was injected together with the $\mathrm{C}^{14}$-mevalonate, resulting in the labeling of cholesterol and desmosterol with different isotopes. Comparison of the serum specific activity curves for the two sterols ( $\mathrm{C}^{14}$-desmosterol and $\mathrm{H}^{3}$-cholesterol) showed that their disappearance rates were fairly similar, desmosterol disappearance being a little more rapid than that of cholesterol. Calculation of the overall metabolism of desmosterol from the doubleisotope data indicated that in this patient only $21 \pm 4$ per cent of the desmosterol that disappeared from the metabolically active pool reappeared therein as cholesterol. Approximately three-fourths of desmosterol disappearance, therefore, occurred via noncholesterol pathways.

The specific activity data and other considerations suggest that desmosterol is similar to cholesterol in its ability to serve as a direct precursor for several sterol metabolites-namely, bile acids and steroid hormones.

\section{ACNOWLEDGMENT}

The authors are greatly indebted to Dr. Daniel Steinberg for advice in the design and conduct of these studies, and to Mr. Hugh Vroman and Mr. David W. Ryan for expert technical assistance.

\section{REFERENCES}

1. Goodman, D. S., Avigan, J., and Wilson, H. N. The metabolism of desmosterol in human subjects during triparanol administration. Biochem. Pharmacol. $1961,8,87$.

2. Avigan, J., Steinberg, D., Vroman, H. E., Thompson, M. J., and Mosettig, E. Studies of cholesterol biosynthesis. I. The identification of desmosterol in serum and tissues of animals and man treated with MER-29. J. biol. Chem. 1960, 235, 3123.

3. Steinberg, D., and Avigan, J. Studies of cholesterol biosynthesis. II. The role of desmosterol in the biosynthesis of cholesterol. J. biol. Chem. 1960, $235,3127$.

4. Frantz, I. D., Mobberley, M. L., and Schroepfer, G. J., Jr. Effects of MER-29 on the intermediary metabolism of cholesterol. Progr. cardiovasc. Dis. 1960, 2, 511.

5. Steinberg, D., Avigan, J., and Feigelson, E. B. Effects of triparanol (MER-29) on cholesterol bio- synthesis and on blood sterol levels in man. J. clin. Invest. 1961, 40, 884.

6. Avigan, J. A method for incorporating cholesterol and other lipides into serum lipoproteins in vitro. J. biol. Chem. 1959, 234, 787.

7. Norman, A. Separation of conjugated bile acids by partition chromatography. Bile acids and steroids 6. Acta chem. scand. 1953, 7, 1413.

8. Sjövall, J. On the separation of bile acids by partition chromatography; bile acids and steroids. Acta physiol. scand. 1953, 29, 232.

9. Mosbach, E. H., Zomzely, C., and Kendall, F. E. Separation of bile acids by column-partition chromatography. Arch. Biochem. 1954, 48, 95.

10. Mosbach, E. H., Kalinsky, H. J., Halpern, E., and Kendall, F. E. Determination of deoxycholic and cholic acids in bile. Arch. Biochem. 1954, 51, 402.

11. Wilson, H., Borris, J. J., and Garrison, M. M. Chromatographic procedure for the determination of urinary corticosteroids and $\mathrm{C}_{18}$ steroids. J. clin. Endocr. 1958, 18, 643.

12. Wilson, H., Lipsett, M. B., and Butler, L. C. Steroid excretion in hypophysectomized women, and the initial effects of corticotropin: A study in urinary steroid patterns. J. clin. Endocr. 1960, 20, 534.

13. Wotiz, H. H., Lemon, H. M., and Marcus, P. Determination of urinary 11-oxygenated 17-ketogenic steroids. J. clin. Endocr. 1957, 17, 116.

14. Bush, I. E. Methods of paper chromatography of steroids applicable to the study of steroids in mammalian blood and tissues. Biochem. J. 1952, 50, 370.

15. Wilson, $\mathrm{H}$. Chromogenic values of various ketosteroids in a micro modification of the Zimmermann reaction: Comparison with the macro procedure. Arch. Biochem. 1954, 52, 217.

16. Cornforth, J. W., Cornforth, R. H., Popjak, G., and Gore, I. Y. Studies on the biosynthesis of cholesterol. 5. Biosynthesis of squalene from DL-3hydroxy-3-methyl- $\left(2-{ }^{14} \mathrm{C}\right)$ pentano-5-lactone. Biochem. J. 1958, 69, 146.

17. Isler, O., Rüegg, R., Würsch, J., Gey, K. F., and Pletscher, A. Zur Biosynthese des Cholesterins aus $\beta, \delta$-Dihydroxy- $\beta$-Methyl-Valeriansäure. Helv. chim. Acta 1957, 40, 2369.

18. Constantopoulos, G., and Tchen, T. T. Cleavage of cholesterol sidechain by adrenal cortex. I. Cofactor requirement and product of cleavage. J. biol. Chem. 1961, 236, 65.

19. Bergstrom, S., Lindstedt, S., Samuelson, B., Corey, E. J., and Gregoriou, G. A. The stereochemistry of 7- $\alpha$-hydroxylation in the biosynthesis of cholic acid from cholesterol. J. Amer. chem. Soc. 1958, 80, 2337.

20. Lindstedt, S., and Sjövall, J. The formation of deoxycholic acid from cholic acid in the rabbit. Acta chem. scand. 1957, 11, 421.

21. Popjak, G., and Cornforth, J. W. The biosynthesis of cholesterol. Advanc. Enzymol. 1960, 22, 281. 
22. Christophe, J., and Popjak, G. Studies on the biosynthesis of cholesterol. XIV. The origin of prenoic acids from allyl pyrophosphates in liver enzyme systems. J. Lip. Res. 1961, 2, 244.

23. Rosenfeld, R. S., and Hellman, L. The relation of plasma and biliary cholesterol to bile acid synthesis in man. J. clin. Invest. 1959, 38, 1334.

24. Werbin, H., and Chaikoff, I. L. Utilization of adrenal gland cholesterol for synthesis of cortisol by the intact normal and the ACTH-treated guinea pig. Arch. Biochem. 1961, 93, 476.

25. Morris, M. D., and Chaikoff, I. L. The origin of cholesterol in liver, small intestine, adrenal gland, and testis in the rat: Dietary versus endogenous contributions. J. biol. Chem. 1959, 234, 1095.
26. Blohm, T. R., Kariya, T., and Mackenzie, R. D. Excretory products of the sterol biosynthetic pathway in the MER-29 treated rat. Excretion of MER-29. Progr. cardiovasc. Dis. 1960, 2, 519.

27. Melby, J. C., St. Cyr, M., and Dale, S. L. Reduction of adrenal-steroid production by an inhibitor of cholesterol biosynthesis. New Engl. J. Med. 1961, 264, 583.

28. Hollander, W., Chobanian, A. V., and Wilkins, R. W. The effects of triparanol (MER-29) in subjects with and without coronary artery disease. J. Amer. med. Ass. 1960, 174, 5.

29. Holloszy, J., and Eisenstein, A. Effect of MER/29 (triparanol) on corticosterone secretion by rat adrenals. Fed. Proc. 1961, 20, 176.

\section{SPECIAL NOTICE TO SUBSCRIBERS}

Post Offices will no longer forward the Journal when you move.

Please notify The Journal of Clinical Investigation, Business Office, 10 Stoughton Street, Boston 18, Mass., at once when you have a change of address, and do not omit the zone number if there is one. 